\title{
Responses of laboratory exposed catfish (Clarias gariepinus) to environmentally relevant concentrations of p,p'-DDT
}

\author{
Kerry Brink ${ }^{a *}$, Johan van Vuren ${ }^{a}$ and Riana Bornman ${ }^{b}$ \\ a Centre for Aquatic Research, Department of Zoology, University of Johannesburg, P.O. Box 524, Auckland Park 2006, \\ Johannesburg, South Africa. \\ b Department of Urology, School of Medicine, University of Pretoria, P.O. Box 667, Pretoria 0001. Pretoria, South Africa. \\ * Corresponding author
}

\begin{abstract}
Technical grade DDT is annually sprayed for malaria control in many under developed countries world wide. Despite the controversy surrounding the use of DDT, minimal research concerning the effects on indigenous fish species in these areas has been conducted. In this study, the objectives were to identify some of the effects of sprayed p,p'-DDT on the common African sharptooth catfish species (Clarias gariepinus) under laboratory conditions. The effects were assessed by exposing specimens to three environmentally relevant concentrations of $p, p^{\prime}-\mathrm{DDT}(0.66,1.36$ and $2.72 \mu \mathrm{g} / \mathrm{l})$ for 21 days and analysing a suite of biomarkers in the plasma, gonads and body morphometrics. The biomarkers were specifically selected based on their practicality in developing countries, which could potentially be utilised for continued monitoring, and included alkali-labile phosphate (ALP), calcium, magnesium and zinc as the indirect measures of vitellogenin, gonadosomatic index, gonad mass manipulated using analysis of covariance, and condition factor. The results showed no significant $(P<0.05)$ dosedependent changes in the plasma, gonads and body condition of $C$. gariepinus, indicating that these species were not responsive to the p,p'-DDT concentrations when exposed sub-chronically. This lack of a response suggested that mature $C$. gariepinus are tolerant to 21 days exposure of low levels of p,p'-DDT.
\end{abstract}

Keywords: p,p'-DDT, laboratory exposures, Clarias gariepinus, biomarkers 
Abbreviations: Indoor Residual Spraying (IRS), Vitellogenin (VTG), Alkali-labile phosphate (ALP), Endocrine Disrupting Chemicals (EDCs), Condition Factor (CF)

\section{Introduction}

The broad spectrum insecticide, dichlorodiphenyltrichloroethane (DDT) is considered to be a persistent and toxic endocrine disrupting chemical (EDC), in the form of o,p'-DDT and p,p'-DDT and its associated metabolites DDE and DDD (ATSDR, 2002). As such, the use of DDT has been banned in many countries under the global, multi-lateral agreement of the Stockholm convention on persistent organic pollutants (POPs) (Bouwman, 2004). However, restricted use has been authorised in some countries as an effective vector control in the fight against malaria (Mabaso et al., 2004).

Technical grade DDT predominantly consists of the active ingredient p,p'-DDT (65-80\%), and to a lesser extent o,p'-DDT (15-21\%), and is most often sprayed in the huts of villages using indoor residual spraying (IRS) techniques (Bornman et al., 2009). The majority of these sprayed areas are under-developed and have relatively limited funding and resources available for research and management of contamination. Consequently, there is still a scarcity of data regarding DDT and its health effects, particularly on indigenous organisms in receiving aquatic ecosystems. It was in this context that the research on the sub-lethal effects from sub-acute p,p'-DDT exposure was initiated in the present study using Clarias gariepinus. The selection of $C$. gariepinus was based on their relatively high frequency of occurrence and abundance within DDT IRS areas, easy handling and relatively sedentary nature (Skelton, 2001). Further advantages for their inclusion are their ability to accumulate large amounts of pollutants without mortality, and indicate DDT effects of organic pollutants (Heath and Claassen, 1999; Mdegela et al., 2010).

Based on previous studies, the exposures to DDT were expected to induce sub-lethal effects primarily associated with endocrine disruption (Ankley and Johnson, 2004; Iwaniuk et al., 2006; Kime, 1998; Vasseur and Cossu-Leguille, 2006). However, inconclusive evidence that DDT induces endocrine disrupting effects in C. gariepinus was shown in the field study by Brink et al. (2012). A range of biomarkers selected based on their ability to identify extent of EDC effects using minimal resources, showed no significant relationship with DDT. Therefore, the aim of this study was to attempt to 
quantify the biomarker responses to DDT exposure in C. gariepinus under more controlled aquarium conditions and to determine the reproductive effects of p,p'-DDT exposure at environmentally relevant concentrations without in situ environmental influences.

The overall suite of biomarkers used was indicative of various levels of effects (Phillips and Rainbow, 1993). Specifically, the levels of alkali-labile phosphate (ALP), calcium (Ca), zinc (Zn) and magnesium (Mg) were selected to indicate sub-cellular changes. According to Bjornsson and Haux (1985) and Lv et al. (2006), these biomarkers can be used as indirect measures of vitellogenin (VTG) concentrations. VTG is an essential protein in female fish reproductive cycle and can be activated in males exposed to oestrogen mimicking compounds, such as DDT (Cheek et al., 2001; Lomax, et al., 1998; Overdorster and Cheek, 2001). Such stimulation of VTG has been induced in male C. gariepinus in the presence of EDCs (Mdegela et al., 2010). However, measurements of VTG are often laborious and expensive, which proves difficult in many developing countries (Marin and Matozzo, 2004; Verslycke et al., 2002). Thus, the specific use of ALP, Ca, Zn and Mg, instead of VTG, was incorporated into this study in order to determine the feasibility of using these relatively simple and cost-effective endpoints to identify DDT induced responses.

In terms of identifying higher level responses, the changes in the catfish gonad and body were assessed, using the gonad somatic index (GSI), analysis of co-variance (ANCOVA) adjusted gonads and condition factor (CF) (Fiest et al., 2005; Sepuveda et al., 2003; Sheahan et al., 2002). The former two are both indicative of gonad condition. Although GSI is the most commonly used index to monitor reproductive cycles (Schweer, 2002), Packard and Boardman (1999) suggested the gonad data rather be adjusted with ANCOVA, than using GSI, in order to remove the obscuring effects of fish mass on gonad mass. Consequently both approaches were incorporated and compared in this study. Whilst the CF was selected as a general biomarker of fish health, which correlates fish body mass to its length using a predicted standardised mass for $C$. gariepinus (Hagenaars et al., 2008). It is based on the assumption that fish mass will decrease due to the depletion in energy resources that are used to cope with the increased stresses posed by a toxicant (Stevenson and Woods, 2006). 
Overall, the objectives of this study were to evaluate these biomarkers and to quantify the responses of the indigenous fish species, C. gariepinus, exposed to p,p'-DDT under laboratory conditions. The results of these analysis were utilised to identify if any biomarkers are suitable in evaluating the effects of environmentally relevant concentrations of $p, p^{\prime}-$ DDT that are probable within a DDT sprayed area.

\section{Materials and Methods}

\subsection{Fish}

Healthy, mature C. gariepinus males (maturity based on body and urogenital papilla size) were obtained from a broodstock of fish bred at Bushveld catfish aquaculture farm near Pretoria, South Africa (De Graaf and Janssen, 1996). The fish were transported to the aquarium facility at the University of Johannesburg and left to acclimate to normal laboratory conditions for 12 weeks. The aquaria received continuous flow of dechlorinated water at $27^{\circ} \mathrm{C}$ and were maintained on a 12 hour light/dark cycle. The fish were fed daily with trout pellets. After the acclimation period, 8 specimens for each exposure set were selected based on body size, health and maturity (Ankley et al., 2001). Each of these fish were transferred into separate $100 \mathrm{~L}$ glass test chambers, where the specimens where further acclimated for an additional six weeks. Water characteristics were monitored daily using a Cyberscan DO100 meter, pHScan meter and cyberscan Con400 and were as follows ( \pm SD): temperature $26.23^{\circ} \mathrm{C} \pm 4.56 ; \mathrm{pH} 7.35 \pm 5.10$; conductivity $271 \mu \mathrm{S} / \mathrm{cm} \pm 90.03$; oxygen saturation $79.94 \% \pm 11.94 ;$ and oxygen levels $7.2 \mathrm{mg} / \mathrm{l} \pm 10.9$.

\subsection{Exposures}

The mature catfish were exposed for 21 days to sub-lethal, environmentally relevant concentrations of $0.659 \mu \mathrm{g} / \mathrm{l}, 1.36 \mu \mathrm{g} / \mathrm{l}$ and $2.724 \mu \mathrm{g} / \mathrm{l}$ p,p'-DDT. According to Ankley and Johnson (2004), 21 days were a suitable exposure period in which to identify endocrine disruptive effects in fish. For each exposure concentration, fish were divided into 2 groups consisting of a solvent control and a p,p'-DDT exposure. Each DDT exposure group contained a separate control group, as solvent levels differed for each exposure group (discussed below). The exposure setup consisted of a flow through system from stock tanks pumped into the $100 \mathrm{~L}$ glass test chambers and maintained by refreshing the 0.659 $\mu \mathrm{g} / \mathrm{l}, 1.36 \mu \mathrm{g} / \mathrm{l}$ and $2.724 \mu \mathrm{g} / \mathrm{l}$ exposure tanks with stock of $0.013 \mu \mathrm{g} / \mathrm{l} / \mathrm{hr}, 0.028 \mu \mathrm{g} / \mathrm{l} / \mathrm{hr}$, and $0.056 \mu \mathrm{g} / \mathrm{l}$ 
/hr, respectively. In the p,p'-DDT stock tanks, the relevant concentrations were obtained by dissolving a nominal quantity of $50 \mathrm{mg} / \mathrm{l}$ p,p'-DDT powder (1,1,1-trichloro-2,2-bis ( $\mathrm{p}$-chlorophenyl)ethane, Sigma) in grade ethanol solvent (Sigma), which did not exceed the $20 \mu \mathrm{g} / \mathrm{l}$ solvent, as recommended by Hutchinson et al. (2006). This solution was then added into the stock tanks containing 900 litres of dechlorinated water in volumes that would make up the required exposure concentrations. Grade ethanol was added to the control tanks in the same volumes that it was added as solvent to the respective DDT exposure groups. During the 21 day exposures, the water quality and fish were monitored and fed as per acclimation period. The discarded contaminated water was put with activated carbon for 1 week before being disposed with biohazard. The actual concentrations of DDT were not confirmed with measurements in this study, but were not expected to deviate drastically. This was assumed as DDT breakdown was not expected to be significant based on the half- life of DDT in water under laboratory conditions range from a couple of days to years depending on conditions (CCME, 2000; Wolfe et al., 1977) and that uptake of DDT in fish from the water is considered relatively rapid (Crawford and Guarino,1976; ATSDR, 2002).

Following exposures, each catfish was weighed (total wet mass, $\mathrm{kg}$ ) and measured (standard length, $\mathrm{cm})$. All fish ranged from $0.6-0.9 \mathrm{~kg}$ and $52-60 \mathrm{~cm}$. Blood samples were then taken from caudal aorta in vacutainers coated with EDTA and aprotinin and kept on ice until centrifuged at $3600 \mathrm{rpm}$ for 10 minutes at $4^{\circ} \mathrm{C}$. The resulting plasma was stored at $-20^{\circ} \mathrm{C}$. After blood was sampled, fish were sacrificed by ethically severing vertebrae (AVMA, 2001) and the gonads were removed and weighed. The pectoral fins were also sampled to estimate the age of the fish. Following the methodology of Staples (1970), sections of approximately $1 \mathrm{~mm}$ were cut perpendicular to the basal recess and placed in grade ethanol solvent (Sigma) until rings were clearly visible. The number of rings were counted and used to estimate age of the catfish, which were between 2 and 4 years.

\subsection{Biomarkers}

The blood was analysed for alkali-labile phosphates (ALP), Ca, Mg and Zn concentrations. ALP was extracted from $10 \mu \mathrm{l}$ of plasma according to the procedure by Brasfield et al. (2002). The extracts were then assayed spectrophotometrically on the universal microplate reader from Biotek Instruments, Inc, using a modified method by Stanton (1968). The metals Ca, Mg and Zn were 
analysed on the Varian UltaMass 700 inductive coupled mass spectrometer (ICP-MS) from $500 \mu \mathrm{l}$ of prepared plasma. All samples were diluted in $1 \%$ nitric acid and digested using a Milestone Ethos microwave, before being analysed. Indium was used as an internal standard to correct for interferences from high-dissolved solids and concentrations of $\mathrm{Zn}$ could only be validated with standard reference material (DOLT-3).

The gonad measurements were used to calculate the gonad condition using the GSI and ANCOVA manipulated data. The GSI was calculated as the percentage of gonad mass $(\mathrm{g})$ to total body mass according to Schweer (2002). For the examination of data by ANCOVA, gonad mass (g) was plotted against fish body mass $(\mathrm{kg})$ for each site of each season. The linear regression lines were then fit to each data set and the sum of squares was measured. The sum of squares was measured by assessing the deviation of the sample mean with the best fit mean. This was then used to determine a common slope between all the groups and utilised to calculate an adjusted mean without effects of body size (Packard and Boardman, 1999). The significance was tested using analysis of variance (ANOVA). All statistical assessments were conducted using SPSS v15.

The body measurement was used to calculate the $\mathrm{CF}$, using the formula $\mathrm{K}=\mathrm{W} /\left(\mathrm{aL}^{\mathrm{b}}\right)$ (Hagenaars et al., 2008). W represents the total body mass $(\mathrm{g})$ and $\mathrm{L}$ the total length $(\mathrm{cm})$, whilst, a and b were the best fit values from the length-mass relationship $\left(W=a L^{b}\right)$ of the total number of fish within the study derived from Graphpad prism v4.

\subsection{Statistical procedures}

The significant variations between control and exposure groups were tested by one-way analysis of variance (ANOVA) using SPSS v.15 (Zar, 1996). The normality was assessed using Shapiro-Wilks to ensure data sets met assumptions of normality (Wang and Riffel, 2011). Homogeneity of variance (Levene's test) was tested prior to applying post-hoc comparisons (Scheffè test for homogeneous or Dunnett's T3 test for non-homogenous data). Significant relationships $(p<0.05)$ between biomarkers and inherent influencing factors were assessed with SPSS v.15 using Pearson's correlation. All graphs were drawn in Graphpad prism v.4 software. 


\section{Results}

\subsection{Plasma ALP, Ca, Mg and Zn}

The plasma ALP, Ca, Mg and $\mathrm{Zn}$ are presented in Figure 1. As is evident from the graphs in this figure, the $\mathrm{Ca}, \mathrm{Mg}$ and $\mathrm{Zn}$ concentrations showed no significant $(\mathrm{P}<0.05)$ differences between control and exposed fish. The ALP concentrations were only measured for in the males exposed to 1.36 and $2.72 \mu \mathrm{g} / \mathrm{l}$ p,p'-DDT, since there was not enough plasma sampled from the males exposed to $0.66 \mu \mathrm{g} / \mathrm{l}$ p,p'-DDT. In the specimens exposed to $2.72 \mu \mathrm{g} / \mathrm{DDT}$, the ALP concentrations significantly increased from the solvent control to the exposed specimens. However, it is suspected that the solvent control levels were not accurate indicators of control levels of ALP. This is because plasma concentrations of ALP in the solvent controls during this exposure grouping was much lower (mean of $0.34 \mu \mathrm{g} / \mathrm{mg}$ ) than those observed in control specimens from previous exposure sets that had ALP levels ranging between 2 and $4 \mu \mathrm{g} / \mathrm{mg}$ and a mean of $2.25 \mu \mathrm{g} / \mathrm{mg}$. The possible effects of the increased ethanol concentrations could neither be discounted.

Table 1: Pearson's correlation between biomarkers and p,p'-DDT and biotic fluctuations. The asterisks represent significant differences $(p<0.05)$.

\begin{tabular}{lrrrrrr}
\hline & ALP & Ca & Mg & Zn & GSI & CF \\
\hline $\mathbf{p}, \mathbf{p}^{\prime}$-DDT & 0.28 & 0.26 & 0.19 & -0.08 & 0.00 & 0.07 \\
Biomarkers & & & & & \\
Ca & & & & & \\
Mg & $* 0.41$ & & & & \\
Zn & $* 0.59$ & $* 0.56$ & & & \\
GSI & -0.01 & 0.32 & -0.24 & & & \\
CF & 0.09 & 0.27 & 0.09 & -0.04 & & \\
& -0.14 & 0.07 & 0.09 & 0.22 & 0.21 & \\
Biotic fluctuations & & & & & \\
Age & & & & & \\
Body length & -0.20 & 0.07 & -0.24 & 0.36 & -0.07 & 0.11 \\
Body mass & 0.01 & -0.04 & -0.08 & $* 0.44$ & 0.07 & $* 0.30$ \\
Gonad mass & -0.01 & -0.02 & -0.20 & $* 0.42$ & 0.06 & $* 0.74$ \\
\hline
\end{tabular}

In order to identify if any of the biomarkers were related, a Pearson's correlation was performed on each of the plasma concentrations (Table 1). The results indicated that there was a significant $(p<0.05)$ positive relationship between ALP, $\mathrm{Ca}$ and $\mathrm{Mg}$ concentrations in the plasma (Table 1). These suggest that the biomarkers could indeed be related. Pearson's correlation performed on plasma biomarkers to identify if there was a link with p,p'-DDT levels, as well as biotic parameters such as 

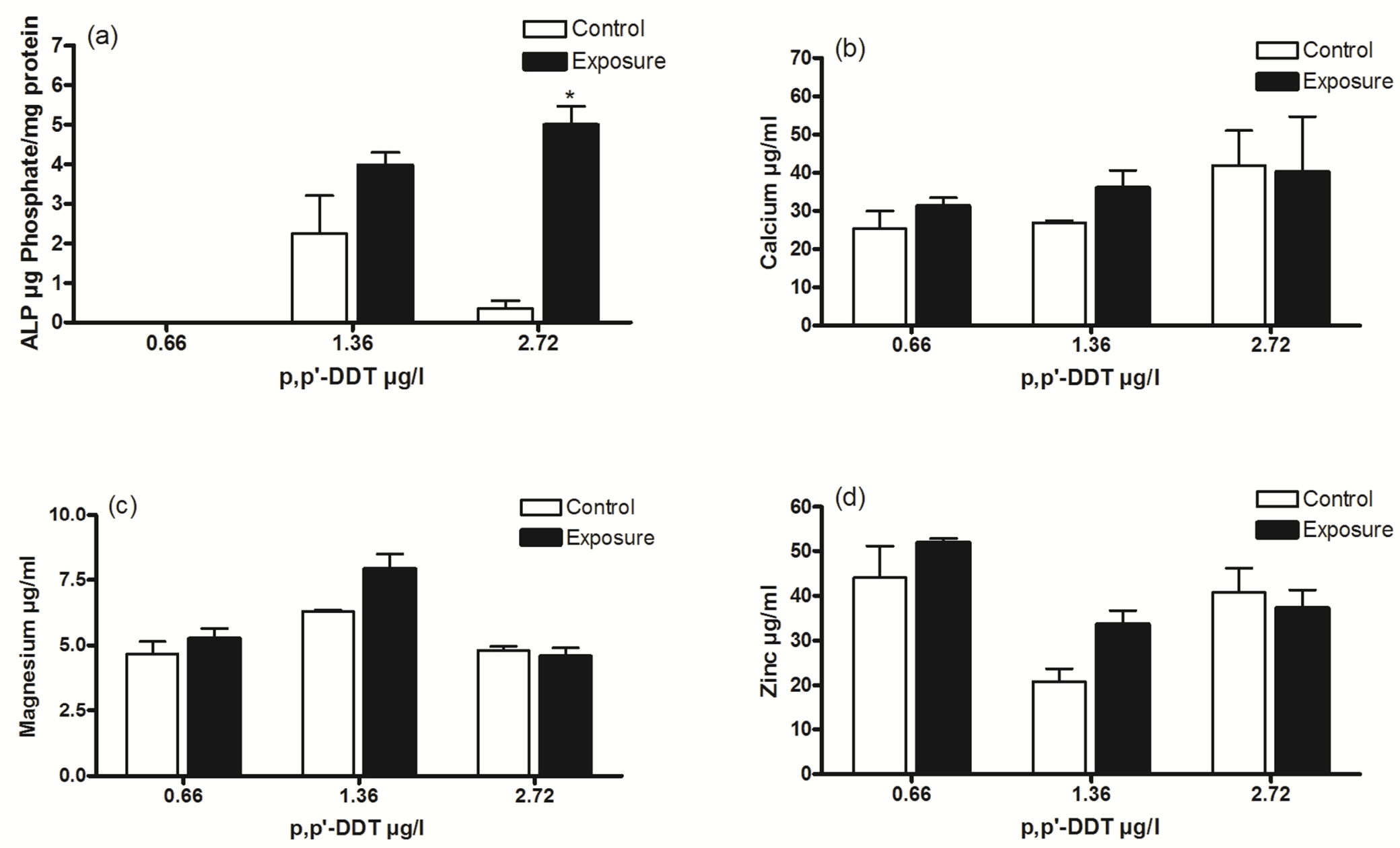

Figure 1: The mean ( \pm SE) plasma alkali-labile phosphate (ALP) (a), calcium (b), magnesium (c) and zinc (d) concentrations in male catfish exposed to $0.66,1.36$, and $2.72 \mu \mathrm{g} / \mathrm{l}$ p,p'-DDT in the ambient water and their respective solvent controls. The asterisks represent significant differences $(p<0.05)$. 
age, size and gonad mass, showed no significant correlations, except for $\mathrm{Zn}$. The $\mathrm{Zn}$ concentrations were significantly $(p<0.05)$ related to the size and mass of the specimens.

\subsection{Gonad condition}

The gonad condition was interpreted with GSI and ANCOVA and represented in Figure 2. Both analyses, showed no significant differences between any of the control and p,p'-DDT exposure groups. All control groups had slightly better gonad condition, except for those exposed to $0.66 \mu \mathrm{g} / \mathrm{l}$ p,p'-DDT, which had a better gonad condition than the control catfish. Upon evaluation of the relationship GSI had with p,p'-DDT, as well as other biomarkers and biotic fluctuating factors in Table 1 , no significant $(p<0.05)$ correlations were observed except for the positive correlation with gonad mass, which was expected as GSI is a direct measure of gonad mass.

\subsection{Condition factor}

In Figure 3, there was very little deviation of the mean CF values between any of the exposure groups. No significant differences were observed, with body condition in the exposure groups showing a tendency to decrease compared to control groups, at 0.66 and $2.72 \mu \mathrm{g} / \mathrm{l}$ p,p'-DDT. Upon evaluation of correlations with influencing factors such as age, length, mass, and gonad mass in Table 1, there were significant $(p<0.05)$ positive relationship in some of the measurements related to size, but none associated with age and the other biomarkers measured in this study.

\section{Discussion}

DDT has been well documented and researched, with numerous studies highlighting its deleterious effects. The most notable of effects have been associated with the endrocrine disruption (Kime, 1998; Pait and Nelson, 2002). Few studies have assessed these effects on C. gariepinus, however, there has been indication that $C$. gariepinus are influenced by endocrine disruption in the presence of EDCs (Bornman et al., 2007; Braathen et al., 2009). This susceptibility to endocrine disruption, together with their high frequency of occurrence within IRS areas, made the selection of $C$. gariepinus particularly attractive as a test species in order to identify the still inconclusive effects of DDT in an IRS sprayed area. The results of this study showed that $C$. gariepinus were not responsive to $0.66 \mathrm{ug} / \mathrm{l}, 1.36 \mathrm{ug} / \mathrm{l}$ and 2.72 ug/l p,p'-DDT following 21 day exposure. The results specifically had no significant $(p<0.05)$ 

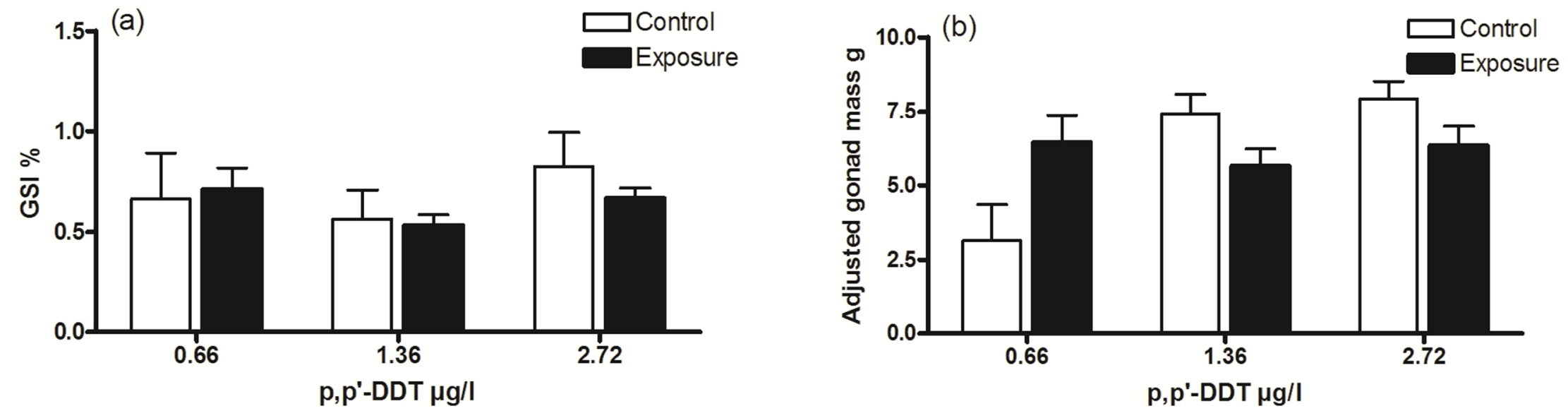

Figure 2: The mean ( \pm SE) gonad condition (GSI) (a) and gonads adjusted with ANCOVA adjusted gonad means (b) in male catfish exposed to $0.66,1.36$ and $2.72 \mu \mathrm{g} / \mathrm{l}$ p,p'-DDT in the ambient water and their respective solvent controls 


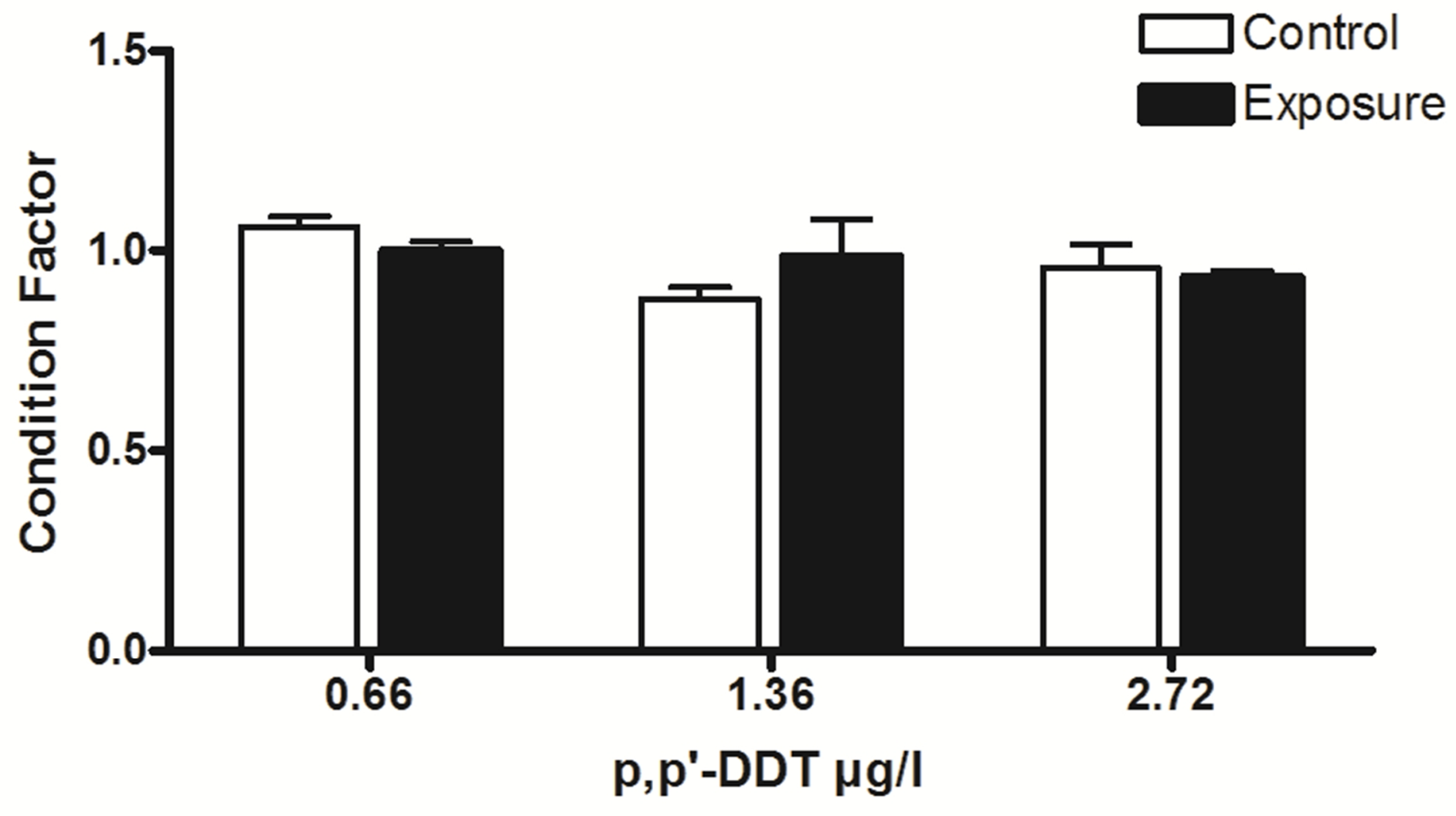

Figure $3:$ The mean $( \pm S E)$ condition factor (CF) in male catfish exposed to $0.66,1.36$ and $2.72 \mu g / l p, p '-D D T$ in the ambient water and their respective solvent controls. 
dose-dependent changes in the biomarkers that represented sub-cellular, organ and organ systems responses.

The sub-cellular responses where represented by the plasma levels of ALP, Ca, Mg and $\mathrm{Zn}$. No studies have been found that assess the applicability of these biomarkers in catfish exposed to DDT, but a few have successfully utilised these as biomarkers linked to excessive VTG levels, which is a very sensitive marker of oestrogen exposure in males (Chatterjee et al., 2001; Donohoe and Curtis, 1996; Hinck et al., 2005). In a study by Bjornsson and Haux (1985), there was a significant dosedependent increase in plasma $\mathrm{Ca}, \mathrm{Mg}$ and inorganic phosphate linked to VTG levels in the presence of $17 ß$ estradiol in freshwater rainbow trout, Salmo gairdneri. Similar observations were found with plasma levels of $\mathrm{Ca}$ and $\mathrm{Mg}$ in Chinese loaches (Lv et al. 2006).

Upon utilising these responses as indirect biomarkers of VTG in male catfish exposed to DDT concentrations, it was evident that the overall sensitivity of $C$. gariepinus was much lower than other species. This was indicated by the lack of significant dose-response relationships of plasma Ca, ALP, $\mathrm{Mg}$ and $\mathrm{Zn}$ to sub-acute DDT exposures. However, it should be highlighted that in the study by Lv et al. (2007), VTG was not detected within 28 days of exposure to $17 \beta$-estradiol and only after 35 days of exposure. The authors could not identify the cause of this and could possibly be the same reason(s) for the lack of results in the current study.

In addition to these results, the concept that ALP, Mg, $\mathrm{Zn}$, and $\mathrm{Ca}$ are all major components bound to VTG and can be used as indirect measures of VTG, was not observed in the current study (Gillespie and de Peyster, 2004; Verslycke et al., 2002). Although the VTG levels were not measured directly, the relationship between ALP, Ca, Mg and $\mathrm{Zn}$ was assessed in terms of their respective quantities on the VTG molecule. It has been reported that each $\mathrm{Ca}$ ion binds to each phosphate group and that $\mathrm{Zn}$ binds at half the concentration as $\mathrm{Ca}$, and Mg binds 10 times lower than $\mathrm{Ca}$ (Anderson, 1998; Ghosh and Thomas, 1995; Montorzi et al., 1995). During this study, these relationships were not observed, where $\mathrm{Ca}$ and $\mathrm{Zn}$ concentrations were highest in the plasma. This highlights that these biomarkers are influenced by other internal and environmental factors and should be interpreted with caution if used to identify effects from EDC exposures. These results can also be used to support the inability of 
these biomarkers to identify effects in C. gariepinus with environmentally relevant $p, p^{\prime}-D D T$ concentrations.

In terms of the gonad condition effects, biomarkers that are routinely used to monitor high level DDT impacts did not show any significant dose-response relationships in C. gariepinus in this study. The biomarkers used to measure the gonad condition included GSI and gonad mass treated with ANCOVA. The comparisons between the two approaches showed the same trends and differed with the conclusions of Packard and Boardman (1999). The authors showed that the GSI should not be utilised at all and that ANCOVA treated gonads were a far better indication of gonad condition. The possible reason of this observation could be due to the general lack of effects observed in the $C$. gariepinus gonads. Nevertheless, the overall weak association between gonad condition and low DDT concentrations were similar to a study done by Tricklebank et al. (2002). In the study, there were no relationships between gonad condition and low DDT levels present in the damselfish (Parma microlepis). In contrast, other fish species have been more responsive to lower concentrations of DDT for example Oreochromis mossambicus showed structural changes in the gonads exposed to DDT concentrations in the water as low as $1 \mu \mathrm{g} / \mathrm{l}$ (Bhattacharya and Pandey, 1989). Unfortunately the GSI or ANCOVA treated gonads were not measured in the latter so exact comparisons could not be made between the two studies.

Using the CF biomarker the general 'well-being' of individual fish was assessed. The condition of the fish during the experiments in this study remained relatively constant, which was consistent with other studies that have also shown the insensitive nature of the CF to lower pollutant concentrations (Bervoets and Blust, 2003; Pait and Nelson, 2002). These results can be attributed to two main factors. Firstly, the CF is an indicator of effects at a higher level of biological complexity, which only occurs when organisms are extremely stressed following chronic exposure to toxic contaminants. Secondly, CF is largely influenced by naturally fluctuating factors such as age, and breeding activity (Phillips and Rainbow, 1993) and as such these factors could have interfered with the already low changes in body mass that may occur due to the DDT exposures. However, upon evaluation of the correlations with the possible influencing factors, it was shown that age was not a factor in this study. Also, although the gonad condition was significantly related to the CF, this result should be interpreted 
with caution as the gonad capacity is directly proportional to the length and mass of the fish, which are both components of the CF.

In conclusion, the results of this study showed that $C$. gariepinus are not responsive to the exposure of $0.66 \mathrm{ug} / \mathrm{l}, 1.36 \mathrm{ug} / \mathrm{l}$ and $2.72 \mathrm{ug} / / \mathrm{p}, \mathrm{p}^{\prime}-\mathrm{DDT}$ for three weeks. The lack of significant $(p<0.05)$ dosedependent changes in none of the biomarkers representing a range of levels of biological effects, highlighted the inability of these biomarkers to identify environmentally relevant $p, p^{\prime}$-DDT effects in $C$. gariepinus. It was suspected, that the subtle responses to DDT, were not indicative of the biomarkers inability to detect effects, but rather due to the tolerance of the species C. gariepinus to DDT contamination following 21 day exposure. It is recommended that further research is conducted using these biomarkers as indicators of effects at higher concentrations and in more sensitive and susceptible fish species indigenous to DDT-sprayed areas. Furthermore it would prove valuable if more research is done to clarify if there are any further responses of $C$. gariepinus to DDT, utilised more sensitive biomarkers, such as DNA damage, and by exposing fish to longer exposure periods.

\section{Acknowledgments}

Funding obtained from Water Research Commission (WRC), University of Johannesburg and the South African National Research Foundation (NRF).

\section{References}

Anderson, T.A., Levitt, D.G., Banaszak, L.J., 1998. The structural basis of lipid interactions in lipovitellin, a soluble lipoprotein. Structure. 6, 895-909.

Ankley, G.T., Johnson, R.D., 2004. Small fish models for identifying and assessing the effects of endocrine-disrupting chemicals. ILAR. 45(4), 469-480.

Ankley, G.T., Jensen, K.M., Kahl, M.D., Korte, J.J., Makynen, E.A., 2001. Description and evaluation of a short-term reproduction test with the fathead minnow (Pimphales promelas). Environ. Toxicol. Chem. 20(6), 1276-1290. 
ATSDR (Agency for toxic substances and disease registry), 2002. Toxicological Profile for DDT, DDE, DDD. Department of Health and Human Services, Public Health Service, Atlanta. Obtained from official ATSDR website: http://www.atsdr.cdc.gov/ToxProfiles. Retrieved 9/12/2011.

AVMA (American Veterinary Medical Association), 2001. AVMA panel on euthanasia, USA.

Bervoets, L., Blust, R., 2003. Metal concentrations in water, sediment and gudgeon (Gobio gobio) from a pollution gradient: relationship with fish condition factor. Environ. Pollut. 126, 9-19.

Bhattacharya, L., Pandey, K.A., 1989. Inhibition of steroidogenesis and pattern of recovery in the testes of DDT exposed cichlid - Oreochromis mossambicus. Bangladesh. J. Zool. 17,1-14, in: Kime, D.E., 1998. Endocrine Disruption in Fish. Kluwer Academic Publishers, Boston, USA.

Bjornsson, B.T., Haux, C., 1985. Distribution of calcium, magnesium and inorganic phosphate in plasma of estradiol-17 $\beta$ treated rainbow trout. J. Comp. Physiol. 155(B), 347-352.

Bornman, M.S., Van Vuren, J.H.J, Bouwman, H., De Jager, T.C., Genthe, B.B., Barnhoorn, I.E.J., 2007. Endocrine Disruptive activity and the Potential Health Risk in the Rietvlei Nature Reserve. Water Research Commission (WRC), Pretoria. Report No. 1505/1/07.

Bornman, R., De Jager, C., Worku, Z., Farias, P., Reif, S., 2009. DDT and urogenital malformations in newborn boys in a malarial area. BJU Int. 106, 405-411.

Bouwman, H. 2004. South Africa and the Stockholm convention on persistent organic pollutants. S.Afr. J. Sci. 100, 323-328.

Braathen, M., Mdegela, R.H., Correia, D., Rundberget, T., Myburgh, J., Botha, C., Skaare, J.U., Sandvic, M. 2009. Vitellogenin in African sharptooth catfish (Clarias gariepinus): purification, characterization, and ELISA development. J. Toxicol. Environ. Health 72(A), 173-183. 
Brasfield, S.M., Weber, L.P., Talent, L.G., Janz, D.M., 2002. Dose-response and time course relationships for vitellogenin induction in male western fence lizards (Sceloporus occidentalis) exposed to ethinylestradiol. Environ. Toxicol. Chem. 21(7), 1410-1416.

Brink, K., Janse van Vuren, J., Bornman, R. 2012. The lack of endocrine disrupting effects in catfish (Clarias gariepinus) from a DDT sprayed area. Ecotox. Environ. Safe 79, 256-263.

Chatterjee, S., Dasmahapatraa, A.K., Ghosha, R., 2001. Disruption of pituitary-ovarian axis by carbofuran in catfish, Heteropneustes fossilis (Bloch). Comp. Biochem. Physiol. 129(C), 265-273.

Cheek, A.N., Brouwer, T.H., Carroll, S., Manning, S., McLachlan, J.A., Brouwer, M., 2001.

Experimental evaluation of vitellogenin as a predictive biomarker for reproductive disruption. Environ. Health. Persp. 109(7), 168-178.

De Graaf, G.F., Janssen, J.A.L., 1996. Artificial reproduction and pond rearing of the African catfish, Clarias gariepinus in sub-Saharan Africa - A handbook. FAO Fisheries Technical Paper. No 362. Rome, FAO. 109pp.

Donohoe, R.M., Curtis, L.R., 1996. Estrogenic activity of chlordecone, DDT and DDE in juvenile rainbow trout: induction of vitellogenesis and interaction with hepatic estrogen binding sites. Aquat. Toxicol. 36, 31-52.

Fiest, G.W., Webb, M.A.H., Gundersen, D.T., Foster, E.P., Schreck, C.B., Maule, A.G., Fitzpatrick, M.S., 2005. Evidence of detrimental effects of environmental contaminants on growth and reproductive physiology of white sturgeon in impounded areas of the Columbia River. Environ. Health Persp. 113(12), 1675-1682.

Gillespie, D.K., de Peyster, A., 2004. Plasma calcium as a surrogate measure for vitellogenin in fathead minnows (Pimephales promelas). Ecotox. Environ. Safe. 58, 90-95. 
Gosh, P., Thomas, P., 1995. Binding of metals to red drum vitellogenin and incorporation into oocytes. Mar. Environ. Res. 39, 165-168.

Hagenaars, A., Knapen, D, Meyer, I.J., van der Ven, K., Hoff. P., De Coen, W., 2008. Toxicity evaluation of perluoroocatane sulfonate (PFOS) in the liver of common carp (Cyprinus carpio). Aquat. Toxicol. 88, 155-163.

Heath, R.G.M., Claassen, M., 1999. An Overview of the Pesticide and Metal Levels Present in Populations of the Larger Indigenous Fish Species Selected in South African Rivers. Water Research Commission (WRC), Pretoria. Report no: 428/1/99.

Hinck, J.E., Schmitt, C.J., Blazer, V.S., Denslow, N.D., Bartish, T.M., Anderson, P.J., Coyle, J.J., Dethloff, G.M., Tillitt, D.E., 2005. Environmental contaminants and biomarker responses in fish from the Columbia River and its tributaries: spatial and temporal trends. Sci. Total. Environ. 266, 549-578.

Hutchinson, T.H., Shillabeer, N., Winter, M.J., Pickford, D.B., 2006. Acute and chronic effects of carrier solvents in aquatic organisms: a critical review. Aquat. Toxicol. 76, 69-92.

Iwaniuk, A.N., Koperski, D.T., Cheng, K.M., Elliott, J.E., Smith, L.K., Wilson, L.K., Wylie, D.R.W., 2006. The effects of environmental exposure of DDT on the brain of a songbird: changes in structures associated with mating and song. Behav. Brain Res. 173, 1-10.

Kime, D.E., 1998. Endocrine Disruption in Fish. Kluwer Academic Publishers, Boston, USA. pp 4317.

Lomax, D.P., Roubal, W.T., Moore, J.D., Johnson, L.L., 1998. An enzyme linked immunosorbent assay (ELISA) for measuring vitellogenin in English sole (Pleuronectes vetulus): development, validation and cross-reactivity with other pleuronectids. Comp. Biochem. Physiol. 121(B), 425-436. 
Lv, X., Shao, J., Song, M., Zhou, Q., Jiang, G., 2006. Vitellogenic effects of $17 \beta$-estradiol in male Chinese loach (Misgurnus anguillicaudatus). Comp. Biochem. Physiol. 143(C), 127-133.

Lv, X., Shao, J., Song, M., Zhou, Q., Jiang, G., 2007. Vitellogenic effects of $17 \beta$-estradiol and bisphenol A in male Chinese loach (Misgurnus anguillicaudatus). Environ. Toxicol. Phar. 24(2), 155159.

Mabaso, M.L.H., Sharp, B., Lengeler, C., 2004. Historical review of malaria control in southern Africa with an emphasis on the use of indoor residual house-spraying. Trop. Med. Int. Health 9, 846-856.

Marin, M.G., Matozzo, V., 2004. Vitellogenin induction as a biomarker of exposure to estrogenic compounds in aquatic environments. Mar. Pollut. Bull. 48, 835-839.

Mdegela, R.H., Braathen, M., Mosha, R.D., SKaare, J.U., Sandvik, M., 2010. Assessment of pollution in sewage ponds using biomarker responses in wild African sharptooth catfish (Clarias gariepinus) in Tanzania. Ecotoxicology. 19, 722-734.

Montorzi, M., Falchuk, K.H., Vallee, B.L., 1995. Vitellogenin and lipovitellin: zinc proteins of Xenopus laevis oocytes. Biochemistry. 34, 10851-10858.

Overdorster, E., Cheek, A.O., 2001. Gender benders at the beach: endocrine disruption in marine and estuarine organisms. Environ. Toxicol. Chem. 20, 23-36.

Packard, G.C., Boardman, T.J., 1999. The use of percentages and size-specific indices to normalize physiological data for variation in body size: wasted time, wasted effort? Comp. Biochem. Physiol. $122,37-44$.

Pait, A.S., Nelson, J.O., 2002. Endocrine Disruption in Fish: An Assessment of Recent Research and Results. NOAA, NOS, Centre for Coastal Monitoring and Assessment, Silver Spring, Maryland. pp246 
Papoulias, D.M., Villalobos, S.A., Meadows, J., Noltie, D.B., Giesy, J.P., Tillitt, D.E., 2003. In Ovo exposure to o,p'-DDE affects sexual development but not sexual differentiation in Japanese Medaka (Oryzias latipes). Environ. Health Persp. 2003. 11(1), 29-32.

Phillips, D.J.H., Rainbow, P.S., 1993. Biomonitoring of Trace Aquatic Contaminants. Chapman and Hall, Oxford, pp. 179-345.

Schweer, G. 2002. Draft Detailed Review Paper on a Fish Two-generation Toxicity Test. EPA, Battelle, Report No. 68-W-01-02.

Sepuveda, M.S., Quinn, B.P., Denslow, N.D., Holm, S.E., Gross, T.S., 2003. Effects of pulp and paper mill effluents on reproductive success of largemouth bass. Environ. Toxcol. Chem. 22, 205-213.

Sheahan, D.A., Brightly, G.C., Daniel, M., Jobling, S., Harries, J.E., Hurst, M.R., et al. 2002.

Reduction in the estrogenic activity of a treated sewage effluent discharge to an English river as a result of a decrease in the concentration of industrially derived surfactants. Environ. Toxicol. Chem. $21,515-519$.

Skelton, P., 2001. A complete guide to the freshwater fish of Southern Africa. Struik Publishers, Cape Town, pp. 231-232.

Stanton, M.G., 1968. Colorimetric determination of inorganic phosphate in the presence of biological material and adenosine triphosphate. Anal. Biochem. 22, 27-34.

Staples, D.J., 1970. Methods of ageing red gurnard (Teleosti: Triglidae) by fin rays and otoliths. N.Z. J. Mar. Freshwat. Res. 5(1), 70-79.

Stevenson, R.D., Woods, W.A., 2006. Condition indices for conservation: new uses for evolving tools. Integr. Comp. Biol. 26(6), 1169-1190. 
Tricklebank, K.A., Kingsford, M.J., Rose, H.A., 2002. Organochlorine pesticides and hexachlorobenzene along the central coast of New South Wales: multi-scale distributions using the territorial damselfish Parma microlepis as an indicator. Environ. Pollut. 116, 319-335.

Vasseur, P., Cossu-Leguille, C., 2006. Linking molecular interactions to consequent effects of persistent organic pollutants (POPs) upon populations. Chemosphere. 62, 1033-1042.

Verslycke, T., Vandenbergh, G.F., Versonnen, B., Arijs, K., Janssen, C.R., 2002. Induction of vitellogenesis in 17a-ethinylestradiol-exposed rainbow trout (Oncorhynchus mykiss): a method comparison. Comp. Biochem. Physiol. 132(C), 483-492.

Wang, M., Riffel, M. 2011. Making the right conclusions based on wrong results and small sample sizes: interpretation of statistical tests in ecotoxicology. Ecotox. Environ. Safe. 74(4), 684-692.

Zar, J.H., 1996. Biostatistical analysis. Prentice-hall, New Jersey. pp139-248 